\title{
O DIREITO DE MORRER DIGNAMENTE: UM ESTUDO SOB A LUZ DO TESTAMENTO VITAL E DO PRINCÍPIO DA AUTONOMIA PRIVADA DA VONTADE ${ }^{1}$
}

THE RIGHT TO DIE DENTALLY: A STUDY UNDER THE LIGHT OF VITAL TESTAMENT AND THE PRINCIPLE OF PRIVATE WILL AUTONOMY

Amanda Ramaiane MORANDO

Fabiana Maria Martins Gomes de CASTRO ${ }^{3}$

ISSUE DOI: 10.21207/2675-0104.2018.771

\footnotetext{
${ }^{1} \mathrm{O}$ presente artigo sintetiza a monografia de conclusão da pesquisa, realizada para o Programa Interno de Bolsas de Iniciação Científica (PIBIC 2017-2018) da Faculdade de Direito de Franca (FDF), Franca/SP.

${ }^{2}$ Discente da Faculdade de Direito de Franca (FDF), Franca/SP. Bolsista do Programa Interno de Bolsas de Iniciação Científica (PIBIC 2017-2018).

${ }^{3}$ Doutora em Direito - Efetividade do Direito, subárea Direito Civil pela Pontifícia Universidade Católica de São Paulo (2016). Mestre em Direito das Obrigações pela Universidade Estadual Paulista Júlio de Mesquita Filho - Campus Franca/SP (2003). Graduação em Ciências Sociais e Jurídicas Aplicadas - Faculdades Integradas Toledo Araçatuba (1998). Advogada. Professora Titular da disciplina Direito Civil II na Faculdade de Direito de Franca. Professor de Ensino Superior III-E da Faculdade de Tecnologia de Mococa - Fatec Mococa (desde agosto de 2008) e Diretora da Faculdade de Tecnologia de Mococa (Gestão 2017/2021). Experiência em Regulação do Ensino Superior desde 2018 como Avaliador de Cursos do Banco de Avaliadores do SINAES - INEP. Experiência na área de Direito Civil, Direito Processual Civil, Direito do Consumidor, Teoria Geral do Direito e Direito Empresarial. Coordenadora Acadêmica do Curso de Direito na Faculdade de Ciências Agrárias e Sociais - FAIT (2002/2005). Coordenadora do Núcleo de Prática Jurídica - UNIFEG (2007 a 2011), conforme Portaria 006/2007. Membro do Núcleo Docente Estruturante - UNIFEG (2009/2011). Assistente Técnico Administrativo I (Cargo em Confiança 10/2010 a 07/2017) na Faculdade de Tecnologia de Mococa. Professor do Centro Universitário da Fundação Educacional Guaxupé UNIFEG (2005/2012 e 2014/2017). Professora na Faculdade de Ciências Agrárias e Sociais - FAIT (2002/2007).
} 


\title{
RESUMO
}

O propósito do presente artigo é identificar se há no ordenamento jurídico pátrio o reconhecimento da liberdade e autodeterminação para fazer valer o princípio da dignidade da pessoa humana, tendo por enfoque central o testamento vital. Pois, diante da valorização da dignidade da pessoa humana, permitese a conclusão de uma vida da forma mais integra e menos dolorosa possível, perto de quem se ama e da forma como se pretende. Utiliza-se, para tanto, o método dedutivo, por meio de um procedimento técnico-bibliográfico sobre o tema, empregando ensinamentos doutrinários e jurisprudenciais, na análise de um acórdão brasileiro, bem como dados secundários, como artigos e teses já publicadas acerca do assunto. É oportuno destacar que, no direito pátrio, ainda não há legislação clara e específica sobre o tema, apoiando-se este, basilarmente, em princípios constitucionais e bioéticos, no Código Civil e nas Resoluções do Conselho Federal de Medicina que traduzem a validade e aplicabilidade da declaração do enfermo sob a forma de testamento vital no contexto jurídico brasileiro. Desta feita, o artigo impinge verificar que o paciente terminal deve ser tratado de modo digno, conforme seus valores, suas crenças ou convicções pessoais, recebendo cuidados paliativos para amenizar o seu sofrer, a fim de assegurar-lhe a qualidade de vida, em virtude de o ser humano possuir outras dimensões que não somente a biológica.

Palavras-chave: Testamento vital. Autonomia da vontade. Direito à morte digna.

\begin{abstract}
This article aims is to identify whether there is in the national legal system the recognition of freedom and self-determination to uphold the principle of the dignity of the human person, with a central focus on the living will.. For, given the value of the dignity of the human person, it is possible to conclude a life in the most integrated and least painful way possible, close to those who love themselves and the way in which they are intended To accomplish this goal, this research employs the deductive method, taking advantage of a technical-bibliographical procedure on the theme, employing doctrinal and jurisprudential teachings, in the analysis of a Brazilian judgment, as well as secondary data, such as articles and theses already published on the subject. It should be pointed out that, in the country's law, there is still no clear and specific legislation on the theme, basically based on constitutional and bioethical principles, the Civil Code and the Resolutions of the Federal Medical Council that reflect the validity and applicability of the patient's declaration in the form of a living will in the Brazilian legal context. The article impinges on verifying that the terminal patient should be treated in a dignified manner, according to his personal values, beliefs or convictions, receiving palliative care to ease his suffering, in order to assure him the quality of life, by virtue of human being has dimensions other than biological.
\end{abstract}

Keywords: Living will. Autonomy of Will. Right to a dignified death

O Estado Democrático de Direito, no qual o ser humano se encontra inserido, privilegia o direito à vida e a dignidade da pessoa humana, possibilitando maior chance de as pessoas que não mais possuem capacidade de viver de forma digna, em razão de quadro clínico irreversível, o direito de recusar a manutenção da vida que somente se sustenta com base em parafernálias tecnológicas, determinando, com plena consciência, o local e a forma como deseja permanecer nos últimos dias de vida. 
Assim, o propósito do testamento vital é garantir ao indivíduo o direito de dispor sobre seu corpo, sua integridade física, sua saúde e sua própria vida enquanto vivo, para os casos em que venha a ser acometido de moléstia incurável, suprimindo-lhe a capacidade de expressão e de livre manifestação daquilo que almeja.

Isso porque, a ausência de dignidade não mais caracteriza a vivência, mas tão somente a sobrevivência, e dessa forma, se o ser humano, durante o decorrer de sua vida, escolhe o que é melhor para si, é respeitável que lhe haja permissão para também decidir, conscientemente, sobre o momento de sua morte.

Em que pese no Brasil não existir legislação que trata especificamente acerca do testamento vital, porque, em razão da produção de efeitos antes da morte do testador, o referido instituto se afasta do Direito das Sucessões, faz-se presente, em âmbito infralegal, a Resolução do Conselho Federal de Medicina $n^{\circ}$. 1.931/2009, que institui o atual Código de Ética Médica em vigor desde o ano de 2010 e a Resolução do Conselho Federal de Medicina $\mathrm{n}^{\circ}$. 1.995/2012, o qual versa sobre as diretivas antecipadas da vontade, com amparo no Código Civil e na Constituição Federal, ao passo que, diante da ausência de normatização, deve obedecer às normas jurídicas já existentes que proporcionam grande avanço ao reconhecimento da importância da vontade do paciente para a suspensão de tratamentos fúteis.

Quanto à estrutura, o texto encontra-se delimitado em quatro partes, em que, inicialmente, far-se-á uma análise dos direitos fundamentais que, por sua indispensabilidade, visam proteger a pessoa humana, assegurando-lhe uma existência livre, digna e igual. Nessa seara, a pesquisa discorrerá sobre a importância do direito à vida, amplamente resguardado pela Constituição Federal, mas não de caracterização absoluta, dado que, pode ser relativizado em determinadas situações, pois se traduz no direito de viver dignamente e não apenas no direito de sobrevivência. Ademais, a dignidade da pessoa humana, de igual modo, é valorada, dado que pode superar a própria vida, acarretando o florescer da morte, porque se deve permitir a conclusão de uma vida da forma mais integra e menos dolorosa possível, perto de quem se ama e da forma como se pretende. Para tanto, mister tratar sobre a autonomia da vontade, isto é, o auto-regramento, em que o indivíduo tem o poder de decidir se deseja iniciar ou dar continuidade a um tratamento considerado extraordinário para sua doença, que sequer demonstra impossibilidade de melhora ou cura, vedando, portanto, uma existência degradante. 
Continuamente, far-se-á a amostragem da evolução e aplicação do exercício da autonomia para morrer face ao direito brasileiro, uma vez que a manifestação de vontade nas situações de fim da vida está, de forma indissociável, relacionada à dignidade da pessoa humana, motivo pelo qual há de se reconhecer que os atos decididos sob a luz da autonomia privada somente se tomados em conformidade com o princípio constitucional da dignidade humana são válidos e passíveis de reconhecimento pelo ordenamento jurídico vigente. Desta feita, utiliza-se como fundamento o princípio da autonomia privada para a tomada de decisões sobre a própria morte, porque, toda e qualquer intervenção terapêutica realizada contra a vontade do paciente golpeia lhe no tocante à sua dignidade. Dessa maneira, a pesquisa focalizará na importância de saber reconhecer os limites médicos, científicos e tecnológicos, para, de forma sensata e racional aceitá-los, dando ao doente, o poder de retirar-se de qualquer tratamento que prolongue sua vida, permitindo que a morte ocorra de forma natural, controlando e aliviando a dor através de cuidados paliativos, tendo assegurada assistência integral, conforto físico, psíquico, social, espiritual, bem como sua dignidade.

Em sequência, será apresentado o enlace da seara jurídica e da medicina, já que o direito se vale dos princípios bioéticos da autonomia, beneficência, não maleficência e justiça para regular condutas que se mostram cada vez mais presentes no dia-a-dia, mas que, no entanto, ainda não estão determinadas pela lei. Para melhor compreensão do tema a pesquisa traçará as distinções entre eutanásia, distanásia, mistanásia, ortotanásia e o suicídio assistido, por meio da análise das circunstâncias e da prática peculiar de cada uma, tendo em vista que, é por meio por meio destes institutos que se materializa o "direito de morrer", não regulamentado pelo ordenamento jurídico vigente, mas de acontecimento inevitável. Deve prevalecer, nas relações médico-paciente, o consentimento informado, capaz de preservar a liberdade do enfermo, de forma a se distanciar da supremacia do profissional, pois tão somente estimula decisões genuinamente voluntárias de quem, em ultima análise, suportará os efeitos do tratamento.

Derradeiramente, será apresentado o testamento vital, pois, por meio deste documento, é possível alcançar a morte digna, fazendo com que o paciente determine, antecipadamente e enquanto consciente, a sua vontade, diante de possibilidade de ocorrência de incapacidade futura. Assim, o presente trabalho apresentará a sua a conceituação e requisitos, destacando a tomada de decisões de acordo com a ótica religiosa, cultural 
e de valor pessoal, e, através do direito comparado, analisará, na legislação estrangeira, os pontos favoráveis e desfavoráveis da busca pela positivação do direito de morrer, dentro dos seus limites, visto que alguns países decidiram enfrentar o dilema causado pela possível periculosidade do assunto, regulamentando e legalizando a declaração, para se chegar ao estudo da validade do testamento vital no ordenamento jurídico brasileiro, uma vez que carece de normatização, demonstrando, para tanto, as Resoluções elaboradas pelo Conselho Federal de Medicina. Por fim, traçará um estudo de caso concreto, tendo em vista que, o Tribunal de Justiça do Rio Grande do Sul optou pelo reconhecimento do testamento vital, legitimando a vontade do paciente na escolha do procedimento médico.

Com a pretensão de estabelecer resposta à questão central deste trabalho sobre a possibilidade de se alcançar a morte de digna através do exercício da autonomia privada, utilizando-se, para tanto o testamento vital como forma de exercer a vontade pretendida, já que oportuniza a fruição de sua existência sem qualquer interferência externa.

\section{OS DIREITOS FUNDAMENTAIS E A PROTEÇÃO À PESSOA HUMANA}

Fundamentais são todos os direitos indispensáveis à pessoa humana, necessários para assegurar a todos os indivíduos uma existência digna, livre e igual. Dessa forma, não basta o Estado reconhecê-los formalmente, é preciso também concretizá-los e incorporá-los no dia a dia dos cidadãos e de seus agentes4.

$\mathrm{O}$ direito à vida, inserido no rol dos direitos fundamentais elencados no art. $5^{\circ}$ da Constituição Federal de 1988, é amplamente resguardado, uma vez que, sua proteção é de extrema importância, pois se traduz na existência do ser humano, sendo, portanto, pressuposto para o exercício de todos os outros direitos fundamentais que o homem possui, razão pela qual, se houver violação neste, todos os demais direitos perdem sua razão de ser.

${ }^{4}$ PINHO, Rodrigo César Rebello. Teoria geral da Constituição e direitos fundamentais. 3.ed. rev. São Paulo: Saraiva, 2002. p. 65. v. 17. 
Intrinsecamente ligado à dignidade, o direito à vida se figura no direito de viver dignamente e não apenas no direito de sobreviver, assim sendo, constitui dever estatal, no âmbito constitucional, provê-la e mantêla com tudo o que for necessário para possibilitar uma vivência digna, como a alimentação, a assistência média, a educação, o vestuário, entre outros, expressamente garantidos na Carta Magna5.

Desse modo, razoável se faz a sustentação de que o direito à vida possui um peso abstrato maior, ocupando, portanto, uma posição preferencial, mas, configura equivoco reputar o direito a vida como absoluto e hierarquicamente superior aos demais.

A dignidade da pessoa humana é um piso vital mínimo, ou seja, o mínimo necessário que a ordem constitucional deve assegurar para a existência da pessoa humana, a partir dela identifica-se um núcleo de integridade física e moral que deve ser assegurado a todas as pessoas por sua existência no mundo, relacionando-se com a satisfação espiritual e com as condições materiais de subsistência do ser humano6.

Muitas vezes pelo fato de ser garantida por princípios, caracterizada como plena e absoluta, a dignidade é tida como incompreendida, o que resulta em situações conflitantes no caso concreto, haja vista que todos são iguais em sua dignidade, ainda que não se portem de forma igualmente digna nas relações com o próximo, sendo repudiada toda concepção que considera a dignidade como prestação, ou seja, como dependente das ações individuais de cada qual7.

À vista disso, a dignidade não pode afastada da valorização da vida humana, sob pena de ofensa aos fundamentos do Estado Democrático de Direito, uma vez que, com o objetivo de oferecer proteção ao ser humano, o constitucionalismo contemporâneo veda, de forma total, a degradação e a coisificação do indivíduo.

A autonomia privada visa afastar da decisão do indivíduo influências externas, logo, ele decide por si e para si, de forma a exteriorizar

\footnotetext{
${ }^{5}$ MORAES, Alexandre de. Direitos humanos fundamentais: teoria geral, comentário aos arts. $1^{\circ}$ a $5^{\circ}$ da Constituição da República Federativa do Brasil, doutrina e jurisprudência . 8. ed. São Paulo: Atlas, 2007. p. 76.

${ }^{6}$ FIORILLO, Celso Antonio Pacheco. Curso de direito ambiental brasileiro. 12. ed. rev., atual. eampl. São Paulo, SP: Saraiva, 2011, p. 20 e ss.

${ }^{7}$ MAURER, Beatrice et al. Dimensões da dignidade. In: SARLET, Ingo Wolfgang (Org.). Dimensões da dignidade: ensaio de filosofia do direito e direito constitucional. Porto Alegre, RS: Livraria do Advogado, 2005. p.61.
} 
sua própria vontade e exercer seu direito de escolha quanto a seus objetivos específicos, traçar e realizar os planos de vida, sempre com respeito à limitação imposta pelo ordenamento jurídico vigente. É o que se encontra na disposição do art. $5^{\circ}$, inciso II da Constituição Federal.

De forma intrínseca ao ser humano, a autonomia torna-se legitimada pela dignidade nas situações jurídicas existentes no ordenamento jurídico, que deve garantir tratamento digno e condições mínimas existenciais ao cidadão. Caso em que, não é possível, quando da análise, desassociá-la da dignidade.

Logo, a autonomia também se trata de um direito fundamental, pois, de acordo com Roxana Cardoso Brasileiro Borges, pode ser definida como "o poder atribuído pelo ordenamento jurídico ao indivíduo para que este possa reger, com efeitos jurídicos, suas próprias reações ", habilitando-se tomar decisões em situações específicas da vida, seja em caráter patrimonial ou em caráter existencial ${ }^{9}$.

Assim sendo, com fulcro no princípio da autonomia privada, o individuo tem o arbítrio de se autodeterminar na tomada de decisões antecipadas sobre a própria morte, fazendo com que prevaleça a sua vontade diante das opções médicas a serem seguidas ante a possibilidade de ocorrência de incapacidade futura, ou seja, quando não mais puder o paciente decidir por si próprio.

\section{NO BAILAR DA MORTE, A AUTONOMIA PRIVADA EM CENA}

Da metamorfose que sofreu o processamento do morrer com o passar dos dias, compreende-se que a morte se torna cada vez mais solitária, negada e desprezível a qualidade humana, razão pela qual, a fim de evitá-la se agrega práticas de terapias fúteis, retirando do paciente o domínio do seu próprio morrer, confiscando-lhe, assim a sua dignidade ${ }^{10}$.

\footnotetext{
${ }^{8}$ BORGES, Roxana Cardoso Brasileiro. Disponibilidade dos direitos de personalidade e autonomia privada. São Paulo: Saraiva, 2005. p. 47-48.

${ }^{9}$ DADALTO, Luciana. Testamento Vital. 2. ed. Rio de Janeiro: Lumen Juris, 2013. p. 3234.

${ }^{10}$ MARRERIRO, Cecília Lôbo. O direito à morte digna: uma análise ética e legal da ortotanásia. Curitiba: Appris, 2014, p. 72.
} 
Como característica eminentemente humana, a autonomia traduz-se no poder de estabelecer para si as regras da sua própria conduta ${ }^{11}$. $\mathrm{E}$, atrelada ao princípio da dignidade humana, propicia condições mínimas para desenvolver as potencialidades de cada indivíduo, posto que, se dá o oferecimento de recursos que dispõem a sociedade para a manutenção de uma existência digna ${ }^{12}$, além de proporcionar orientação e aplicação das demais normas presentes no ordenamento jurídico brasileiro.

Por conseguinte, a vida humana é que tem dignidade, da mesma forma que a liberdade do homem também tem dignidade e, dessa forma, ao lecionar, Rosa Maria de Andrade Nery claramente aduz que: "falar-se em dignidade do ser humano é prestigiar-lhe a vida e a liberdade ${ }^{13}$ ".

Tem-se, portanto, que a vontade do doente em estado terminal deve ser preservada, de forma que lhe seja garantido o direito de se manifestar, de forma prévia e consciente, sobre os tratamentos em que deseja ou não ser submetido.

Nos dias atuais deve-se combater o fenômeno da medicalização da vida, repleto de tratamentos fúteis, causadores de imensa dor e sofrimento que tão só postergam o processo de morrer, afastando cada vez mais o indivíduo de uma despedida digna. Considera-se, nesse sentido, que toda e qualquer intervenção terapêutica realizada contra a vontade do paciente golpeia lhe no tocante à sua dignidade.

Perfaz-se, assim, que o respeito à autonomia do enfermo muito contribui para a dignidade no fim da vida, através do investimento a tratamentos que se apresentam com reais benefícios de modo a eliminar qualquer cuidado desnecessário, extremo ou desproporcional.

$\mathrm{O}$ reconhecimento do direito à morte digna no ordenamento jurídico brasileiro garante ao paciente a não ocorrência da prática abusiva do médico com relação ao tratamento fútil, o que gera uma consequência dúplice, posto que, de um lado garante, ao indivíduo debilitado, a dignidade da pessoa humana e a autonomia de vontade, e de outro ao médico a licitude de não prolongar artificialmente a vida humana, se este for o desejo do paciente.

A referida garantia está em conformidade com a orientação jurisprudencial firmada no Enunciado ${ }^{\circ} 37$, aprovado nos dias 14 e 15 de

\footnotetext{
${ }^{11}$ DADALTO, Luciana. Testamento Vital. 3 ed. São Paulo: Atlas, 2015, p. 7-8.

12 Idem, p. 11.

13 Idem, ibidem.
} 
maio de 2014, momento em que o Conselho Nacional de Justiça (CNJ) realizou na cidade de São Paulo, a I Jornada de Direito da Saúde para tratar da manifestação de vontade sobre tratamentos médicos, restringindo assim o conteúdo das diretivas, não dispondo sobre as manifestações de assuntos não médicos, tais como a ocorrência fúnebre, prazo de validade, possibilidade da decisão de incapazes com discernimento, necessidade de lei específica, razão pela qual novos enunciados podem ser publicados para suprir a lacuna existente.

Diante disso, é possível constatar que o Estado possui a incumbência de garantir a vida do homem perante a sociedade e ao próprio Estado, porém, não deve extrapolar e intervir nas questões de foro íntimo, posto que cabe ao próprio cidadão, sem interferências externas, julgar e escolher como na vida se quer viver, propiciando a ele o exercício do direito fundamental à liberdade de vivenciar o processo natural de morrer, ao passo que, inadmite-se a transformação do direito à vida em um dever que sacrifica a dignidade.

\section{O INDISPENSÁVEL ENCONTRO ENTRE A MEDICINA E O DIREITO}

Os progressos na área médica-científica, principalmente na área da saúde são extremamente necessários. Entretanto, a sofisticada e excessiva tecnologia muito contribui para a desumanização do tratamento auferido aos doentes, uma vez que, de forma efetiva, possibilita a prolongação indefinida do processo de morrer ainda que inexista chance de cura, pois os profissionais da saúde se sentem na missão de resguardar a vida de seu processo fim, e se o contrário ocorre, são tidos como fracassados.

Nesse contexto, é perceptível a presença do paternalismo, onde a conduta praticada pelo médico ao estipular os rumos do tratamento era considerada a melhor para o paciente, sem reconhecer os desejos e a autonomia deste, todavia, o mesmo vem sendo desconstituído, visto que já não mais cabe ao profissional da saúde, de forma exclusiva a tomada de decisões, haja vista que ao paciente cabe compartilhar em qual espécie tratamento melhor se adapta às suas expectativas de cura, fazendo jus a sua autonomia e gerando na relação médico-paciente uma situação de igualdade. 
As ações médicas devem sempre ser pautadas racionalmente e de acordo com a sabedoria, de modo a oferecer benefícios ao paciente, contudo, imprescindível se faz sua responsabilidade ao agir com sapiência no momento de praticar a interrupção de um tratamento infrutífero, pois não pode haver negligência quanto à qualidade de vida do indivíduo ${ }^{14}$.

Nesse sentido é o entender de Papa Pio XII, que, ao participar de um Congresso de Anestesiologia realizado em Roma afirma que a obrigação dos médicos na tentativa de salvar a vida se dá até o limite em que é possível o uso de meios normais, ou seja, momento este em que se faz desnecessário o uso de métodos excepcionais ${ }^{15}$.

Acerca da terminalidade da vida há inúmeras indagações a respeito, principalmente quando se tratam da possibilidade de colocá-la a disposição ou não, por meio dos institutos da Eutanásia, Distanásia, Ortotanásia, Mistanásia e Suicídio Assistido, tendo em vista que é por meio destes que se materializa o "direito de morrer", não regulamentado pelo ordenamento jurídico vigente, mas de acontecimento inevitável.

A eutanásia consiste, portanto, na prática de atos de compaixão que visam abreviar a vida do enfermo com o intuito de cessar as dores e sofrimentos deste, bem como daqueles que vivem ao seu redor, por meio de provocação prematura da morte do paciente, caracterizando-se pela presença de dois elementos básicos em sua caracterização: a intenção de beneficiar o doente e o efeito da ação ou omissão praticada.

A ocorrência do suicídio assistido dá-se de forma semelhante à eutanásia, pois consiste na promoção de meios e orientações para que o enfermo coloque fim a sua própria vida, diferenciando-se desta uma vez que, com o devido consentimento, o ato executório causador da morte é praticado pelo próprio paciente e não por terceiros que podem ou não ser profissionais da área médica ${ }^{16}$. Ocorre, no entanto, com a participação material de uma terceira pessoa, que oferece ao doente meio idôneo para que por meio de atos próprios provoque sua morte e coloque fim a toda vida indigna a qual entende estar inserido.

\footnotetext{
${ }^{14}$ MOLLER, Letícia Ludwing. Direito à morte com dignidade e autonomia. Curitiba: Juruá, 2012, p. 62.

${ }^{15}$ DIAS, Maria Berenice. Bioética $e$ Direito. Disponível em: <http://www.mariaberenice.com.br/manager/arq/(cod2_543)1_bioetica_e_direito.pdf > Acesso em 31/07/17 às $17 \mathrm{~h} 10 \mathrm{~min}$.

${ }^{16}$ DADALTO, Luciana. Testamento Vital. Rio de Janeiro: Lúmen Júris, 2010. p. 35.
} 
A mistanásia é também conhecida como eutanásia social ou morte miserável antes do tempo, uma vez que ocorre uma falha no sistema estrutural do Estado em relação à saúde, em decorrência de diversos fatores.

De outra senda, a prática do prolongamento artificial do processo de morte, a qual ocasiona sofrimento para o indivíduo doente é denominada distanásia, também conhecida como futilidade médica ou obstinação terapêutica. Com isso, mesmo que não haja previsão de possibilidade de cura ou melhora por parte da equipe médica, dilata-se a agonia artificial ${ }^{17}$, ou melhor, propicia o prolongamento descomedido da morte de um paciente em fase terminal ou quando o tratamento se faz inútil.

Para tanto, as medidas terapêuticas devem ser buscadas somente quando necessárias e eficazes para a melhora do doente, sempre com respeito aos princípios constitucionais da dignidade da pessoa humana e a autonomia do paciente. Assim, quando não há expectativas de sucesso ou melhora na qualidade de vida do sujeito deve-se procurar amenizar os sintomas e não criar mecanismos para adiar a inevitável morte.

Nesse sentido, faz-se presente a ortotanásia que possui como significado a morte de maneira correta, isto é, sua ocorrência de forma humanizada em seu processo natural, afastando qualquer que seja o prolongamento artificial, isto é, realiza limitação ou a supressão de métodos extraordinários que visam prolongar a vida diante da iminência da morte, mantendo, na maioria dos casos tão somente as medidas ordinárias, quais são os cuidados básicos que visam reduzir a dor e o sofrimento do doente.

Pontifica-se o instituto da ortotanásia na exatidão de ocorrência da morte natural, sem os tratamentos considerados imoderados, ocorridos na distanásia e nem a intervenção por meio de ação ou omissão para que se dê a abreviação da vida, como é na eutanásia.

Entende-se a ortotanásia como uma conduta ética e de manifestações favoráveis por parte da Igreja Católica, posto que, um grande e conhecido exemplo deste instituto é a morte do Papa João Paulo

\footnotetext{
${ }^{17}$ BORGES, Roxana Cardoso Brasileiro. Eutanásia, ortotanásia e distanásia: breves considerações a partir do biodireito brasileiro. Disponível em: <http://www.migalhas.com.br/dePeso/16,MI11097,71043-

Eutanasia+ortotanasia+e+distanasia+breves+consideracoes+a+partir+do>. Acesso em: 25/07/2017 às 19h46min.
} 
II, ocorrida em 2005, quando o Pontífice opta por falecer em seus aposentos, no Vaticano, após longo período lutando contra uma infecção, sem condição de melhora ou qualquer possibilidade de reversão. Diante disso, decide estar cercado por uma equipe de profissionais garantindo seu conforto e bem estar para que possa se despedir de seus entes queridos e discípulos.

A autonomia privada deve ser entendida como o poder de alcançar o interesse individual com observância aos limites constitucionais, isto é, sem afetar a coletividade. Outrossim, no âmbito do direito médico, o consentimento informado é o instrumento capaz de garantir o pleno respeito à autonomia do doente ${ }^{18}$.

Ocorre que, na atualidade, além do simples acesso à informação, é fundamental que o paciente entenda claramente as informações a que teve acesso, decidindo de maneira livre, sem vícios e sem qualquer intervenção externa $^{19}$, ou seja, o consentimento informado consiste na livre convicção do paciente em aceitar ou recusar determinados procedimentos tomando por base os esclarecimentos prestados pelo médico sobre a natureza da intervenção, os riscos, as contraindicações e as vantagens acarretadas.

Calha enfatizar que o consentimento informado denota se o paciente é plenamente capaz de decidir se possui a capacidade de entender a informação material, realizar um julgamento sobre a informação à luz de seus próprios valores, visar um resultado determinado e comunicar livremente seu desejo àqueles que tratam ou procuram saber qual é o seu desejo futuro ${ }^{20}$.

Sendo assim, o direito que o paciente possui ao consentimento livre e esclarecido viabiliza o exercício de sua autonomia, uma vez que baseia sua decisão na revelação de informações verdadeiramente esclarecidas, preservando a sua liberdade, de forma a se distanciar da supremacia do profissional, que, tão somente estimula decisões genuinamente voluntárias de quem, em ultima análise, suportará os efeitos do tratamento.

\footnotetext{
${ }^{18}$ DADALTO, Luciana. Testamento Vital. 3. ed. São Paulo: Atlas, 2015, p. 57.

${ }^{19}$ Idem, p. 58-66.

20 BEAUCHAMP, Tom L; CHILDRESS, James F. Princípios de ética bioética. Apud. DADALTO, Luciana Testamento. 3. ed. São Paulo: Atlas, 2015, p. 74.
} 
As decisões sobre o final da vida são complexas e muitas vezes tomadas quando a capacidade de raciocínio do paciente está prejudicada ou impossibilitada, porque, na aproximação da morte podem ocorrer dois caminhos: medidas para prolongar a vida, combatendo futilmente a morte, ou medidas que permitam o processo de morrer com o mínimo de sofrimento.

Utiliza-se em relação aos tratamentos de saúde desnecessários, que não acarretam perspectiva de melhora o testamento vital para preservar a dignidade do doente no momento de sua morte, bem como a liberdade de manifestar sua vontade de forma expressa, registrado na forma de escritura pública, com a certeza de que se houver necessidade, sua vontade será, prioritariamente, obedecida e respeitada. Refere-se, dessa forma, ao direito e ao desejo antecipado e expressamente manifestado pelo paciente para que este possa ter um fim digno.

No ano de 1969, Luis Kutner propôs, nos Estados Unidos da América, a adoção do Living Will, tipicamente conhecido no Brasil como Testamento Vital, meio pelo qual o indivíduo, consciente e esclarecido, de forma escrita, tem a faculdade de recusar a submissão a tratamentos médicos cujo objetivo é, estritamente, a prorrogação da vida, quando os diagnósticos lhes são desfavoráveis, isto é, em estado de terminalidade, sem qualquer oportunidade de melhora ou cura ${ }^{21}$.

$\mathrm{O}$ fundamento legal do testamento vital é o respeito à autonomia do paciente, o livre arbítrio do ser humano e o princípio constitucional de sua dignidade, e seu direito de decidir sobre os procedimentos médicos que afetem sua integridade corporal e sua saúde, e a manifestação de desejo em receber os cuidados paliativos que tratam da dor e dos sintomas mais desagradáveis quando a morte se aproxima.

Além de garantir a autonomia e a liberdade de escolha do paciente, o referido testamento também auxilia os médicos no que diz respeito à aplicação ou não de um determinado tratamento ao indivíduo incapaz de manifestar seu querer em virtude de uma incapacidade superveniente ou doença que não apresenta probabilidade de cura, a fim de

${ }^{21}$ DADALTO, Luciana. Reflexos jurídicos da Resolução CFM 1.995/12. Revista Bioética, Brasília, DF, n. 21, n.1, p.106-112, 2013. 
evitar que os familiares decidam de forma divergente dos pacientes, pois, diante de assuntos delicados, encontram-se emocionalmente fragilizados ${ }^{22}$.

Em que pese a carência normativa brasileira no que tange a validade das Diretivas Antecipadas da Vontade, com a interpretação integrativa das normas constitucionais e infraconstitucionais é possível penetrar o testamento biológico no ordenamento jurídico pátrio ${ }^{23}$, haja vista que não só a existência de lei torna legal um instituto, pois o ordenamento também é composto de princípios, classificados como normas jurídicas não específicas, com capacidade para legitimar e oferecer interpretação em consonância com determinado caso concreto, observando, para tanto, os requisitos de existência e validade dos demais atos jurídicos, presentes no Código Civil.

Tendo em vista que, no que se refere aos atos jurídicos no ordenamento jurídico pátrio, não vigora o principio da tipicidade e, diante disso, há plena liberdade entre os particulares para instituir categorias de negócios não contemplados em lei, desde que não haja afronta à legislação. Tal liberdade foi reconhecida pelo Conselho de Justiça Federal, na V Jornada de Direito Civil, com o Enunciado n ${ }^{\circ} 528$, o qual estatui: “É válida a declaração de vontade, expressa em documento autêntico, também chamado 'testamento vital' em que a pessoa estabelece disposições sobre o tipo de tratamento de saúde, ou não tratamento, que deseja no caso de se encontrar sem condições para manifestar a sua vontade".

A justificativa apresentada para a aprovação do referido Enunciado fundamenta-se na formalização do negócio jurídico por testamento ou qualquer outro documento autêntico, valendo-se do parágrafo único do art. 1.729 do Código Civil para admitir qualquer documento legitimo no sentido de retratar as declarações sobre o direito à autodeterminação da pessoa quanto aos tratamentos médicos que deseja ser submetida ou recusá-los expressamente.

Apesar de fundamental e de proteção relevante, o direito à vida não está coberto pela irrefutabilidade, visto que, está à mercê de restrições, como ocorre nos casos de legítima defesa e estado de necessidade, os quais

${ }^{22}$ LIPPMAN, Ernesto. Testamento Vital: o direito à dignidade. São Paulo: Matrix, 2013. p. 23.

${ }^{23}$ DADALTO, Luciana. Aspectos registrais das diretivas antecipadas de vontade, 2013. Disponível em: < http://testamentovital.com.br/wp-content/uploads/2014/09/Aspectosregistrais-das-dav-civilistica.com-a.2.n.4.20131.pdf >. Acesso em: 29/11/2017 às 09h10min. 
não cabem à intercessão do Poder Público quando o indivíduo procura defender-se quando a própria vida está em conflito com outro direito de viver $^{24}$.

Há também a ocorrente limitação quando a dignidade da pessoa humana, considerada um direito irrenunciável, inviolável e inalienável sobrepõe-se ao direito à vida, considerado também como fundamental. Assim, ocorre com o aborto necessário, o aborto humanitário, a anencefalia e a ortotanásia, por exemplo ${ }^{25}$.

No dia 20 de novembro de 2013, a $1^{\text {a }}$ Câmara Cível do Tribunal de Justiça do Rio Grande do Sul, em votação unânime, optou pelo reconhecimento do testamento vital, legitimando a vontade do paciente quando à escolha do procedimento médico, cuja ementa segue transcrita:

\begin{abstract}
APELAÇÃO CÍVEL. ASSISTÊNCIA À SAÚDE. BIODIREITO. ORTOTANÁSIA. TESTAMENTO VITAL. 1. Se o paciente, com o pé esquerdo necrosado, se nega à amputação, preferindo, conforme laudo psicológico, morrer para "aliviar o sofrimento"; e, conforme laudo psiquiátrico, se encontra em pleno gozo das faculdades mentais, o Estado não pode invadir seu corpo e realizar a cirurgia mutilatória contra a sua vontade, mesmo que seja pelo motivo nobre de salvar sua vida. 2 . O caso se insere no denominado biodireito, na dimensão da ortotanásia, que vem a ser a morte no seu devido tempo, sem prolongar a vida por meios artificiais, ou além do que seria o processo natural. 3. O direito à vida garantido no art. $5^{\circ}$, caput, deve ser combinado com o princípio da dignidade da pessoa, previsto no art. $2^{\circ}$, III, ambos da CF, isto é, vida com dignidade ou razoável qualidade. A Constituição institui o direito à vida, não o dever à vida, razão pela qual não se admite que o paciente seja obrigado a se submeter a tratamento ou cirurgia, máxime quando mutilatória. Ademais, na esfera infraconstitucional, o fato de o art. 15 do CC proibir tratamento médico ou intervenção cirúrgica quando há risco de vida, não quer dizer que, não havendo risco, ou mesmo quando para salvar a vida, a pessoa pode ser constrangida a tal. 4 . Nas circunstâncias, a fim de preservar o médico de eventual acusação de terceiros, tem-se que o paciente, pelo quanto consta nos autos, fez o denominado testamento vital, que figura na Resolução $\mathrm{n}^{\circ}$ 1995/2012, do Conselho Federal de Medicina. 5. Apelação desprovida ${ }^{26}$.
\end{abstract}

\footnotetext{
${ }^{24}$ TAVARES, André Ramos. Curso de direito constitucional. 7. ed. São Paulo: Saraiva, 2009. p. 549.

${ }^{25}$ CAMORE, Francielle Messias. Relativização do direito à vida. JusBrasil. Disponivel em: < https://franciellecamore.jusbrasil.com.br/artigos/491650640/relativizacao-do-direito-avida> Acesso em 09/12/2017 às 22h10min.

${ }^{26}$ Apelação Cível No 70054988266, Primeira Câmara Cível, Tribunal de Justiça do RS, Relator: Irineu Mariani, Julgado em 20/11/2013. Disponivel em: https://tj-
} 
Ao proferir seu voto, o relator, desembargador Irineu Mariani, reconheceu no caso sub judice a presença do instituto da ortotanásia e, diante da recusa do doente ao ato cirúrgico multilatório, ponderou que o Estado não pode invadir a esfera e proceder de forma contrária a sua vontade, mesmo que com o intuito de resgatar sua vida.

O testamento vital, em seu conteúdo, trata da recusa ou aceitação de cuidados que alongam artificialmente a vida humana, inexistindo qualquer melhora ou possibilidade de cura, porém, não cabe ao indivíduo a disposição ou recusa dos cuidados paliativos, garantidos pelos princípios da dignidade da pessoa humana e da morte digna, bem como por demonstrar contrariedade à ética médica.

A aceitação das diretivas antecipadas de vontade se traduz na recusa de tratamentos extraordinários, que visam somente o prolongamento desenfreado da vida, tendo por objetivo garantir ao paciente o atendimento de seus desejos no momento de incapacidade e terminalidade da vida, bem como proporcionar ao médico um respaldo legal para a tomada de complexas decisões.

\section{CONSIDERAÇÕES FINAIS}

É possível observar que a aceitação das diretivas antecipadas de vontade diz respeito à recusa de tratamentos extraordinários, que somente o prolongam a vida de maneira desenfreada, garantindo ao paciente o atendimento de seus desejos no momento de incapacidade e terminalidade da vida, proporcionando ao médico um respaldo legal para a tomada de complexas decisões.

O caráter vinculante das diretivas faz-se necessário para que não ocorra a "jurisdicionalização" do morrer, que seria de inevitável ocorrência diante da recusa do profissional da saúde em executá-las, ignorando a decisão do paciente. Diante disso, o propósito do testamento vital, especificamente tratado neste trabalho, é garantir ao indivíduo o direito de dispor sobre seu corpo, sua integridade física, sua saúde e sua própria vida

rs.jusbrasil.com.br/jurisprudencia/113430626/apelacao-civel-ac-70054988266-rs Acesso em: 29/11/2017 às $11 \mathrm{~h} 37 \mathrm{~min}$ 
para os casos em que venha a ser acometido de moléstia incurável, suprimindo-lhe a capacidade de expressão e de livre manifestação.

A morte digna constitui objeto de complexas e incessantes discussões no direito brasileiro, pois, se de um lado há quem se posicione favorável à referida prática, justificando-a com o princípio da autonomia da vontade, previsto de forma implícita na Carta Magna, cuja finalidade é resguardar a liberdade de escolha do indivíduo, isto é, autodeterminar-se, de outro, há quem se manifeste de modo contrário, por entender que a vida se trata de um direito indisponível e superior aos demais.

Entretanto, é sabido que, no ordenamento jurídico vigente, ainda que fundamental e indispensável, não há direito ilimitado, diante da existência de limites éticos, morais e jurídicos que restringem o seu exercício. E assim ocorre com o direito à vida, ao passo que, mesmo eivado de importância fundamental, sua tutela não é absoluta, como, por exemplo, nos casos de legítima defesa, estado de necessidade, aborto necessário, aborto humanitário, anencefalia e ortotanásia.

Quando ocorre a ausência de dignidade, não mais se faz presente a caracterização da vivência, mas tão somente a sobrevivência, baseando a preservação da dignidade da pessoa em sua morte de forma justa e ética, porque, se o ser humano escolhe o que é melhor para si durante o decorrer de sua vida, é respeitável que lhe haja permissão para também decidir, conscientemente, sobre o momento de sua morte.

Não se trata de pleitear a legalização do suicídio, mas permitir que, em determinadas situações, a pessoa tenha a prerrogativa de recusar a prática de tratamento desumano em si, por meio do testamento vital, redigido e assinado mediante lucidez mental e de forma autônoma, quando, em decorrência de uma doença insuscetível de melhora, futuramente não conseguir expressar sua vontade.

Não obstante, vale salientar que necessária se faz a criação de uma legislação específica sobre as diretivas antecipadas da vontade, pois as lacunas presentes dificultam o entendimento. Contudo, a inexistência de regras não impede a invalidade do testamento vital, haja vista que não só a existência de lei torna legal um instituto, pois o ordenamento também é composto de princípios, classificados como normas jurídicas não específicas, com capacidade para legitimar e oferecer interpretação em consonância com determinado caso concreto, observando, para tanto, os requisitos de existência e validade dos demais atos jurídicos, presentes no Código Civil. 
$\mathrm{Na}$ atualidade, de forma fundamentada e objetiva, o acórdão proferido pela $1^{\mathrm{a}}$ Câmara Cível do Tribunal de Justiça do Rio Grande do Sul afasta-se de uma visão conservadora sobre o assunto, protegendo a dignidade e autonomia do paciente, assegurando-lhe o direito à morte digna, trazendo licitude às diretivas antecipadas da vontade, tendo em vista que, por se tratar de garantia humanística, independe de positivação.

No entanto, a regulamentação legal do instituto traria maior publicidade e garantia para que o instrumento fosse, indubitavelmente, respeitado pelos profissionais da saúde e pela família do paciente, que muitas vezes, de forma egoísta, prefere o sofrer à dignidade do enfermo.

De forma incontestável, faz-se necessária a tutela do direito à vida, contudo, mister também tutelar o direito à morte digna. Assim, para que haja efetivo respeito a essa garantia, diante da indignidade da vida prolongada artificialmente, deve-se deixar morrer, no lugar de forçosamente se fazer viver.

\section{REFERÊNCIAS BIBLIOGRÁFICAS}

BORGES, Roxana Cardoso Brasileiro. Disponibilidade dos direitos de personalidade e autonomia privada. São Paulo: Saraiva, 2005.

BORGES, Roxana Cardoso Brasileiro. Eutanásia, ortotanásia e distanásia: breves considerações a partir do biodireito brasileiro. Disponível em:

<http://www.migalhas.com.br/dePeso/16,MI11097,71043-

Eutanasia+ortotanasia+e+distanasia+breves+consideracoes+a+partir+do>. Acesso em: 25/07/2017 às $19 \mathrm{~h} 46 \mathrm{~min}$.

CAMORE, Francielle Messias. Relativização do direito à vida. JusBrasil. Disponivel em: < https://franciellecamore.jusbrasil.com.br/artigos/491650640/relativizacao-do-direito-a-vida> Acesso em 09/12/2017 às 22h10min.

DADALTO, Luciana. Aspectos registrais das diretivas antecipadas de vontade. 2013. Disponível em: $<$ http://testamentovital.com.br/wp-content/uploads/2014/09/Aspectos-registrais-das-davcivilistica.com-a.2.n.4.20131.pdf >. Acesso em: 29/11/2017 às 09h10min.

DADALTO, Luciana. Reflexos jurídicos da Resolução CFM 1.995/12. Revista Bioética, Brasília, DF, n. 21, n.1, p.106-112, 2013.

DADALTO, Luciana. Testamento Vital. 2. ed. Rio de Janeiro: Lumen Juris, 2013.

DADALTO, Luciana. Testamento Vital. 3 ed. São Paulo: Atlas, 2015. 
DIAS, Maria Berenice. Bioética e Direito. Disponível em:

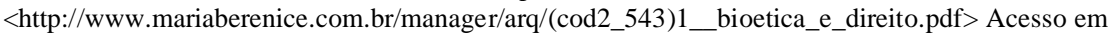
$31 / 07 / 17$ às $17 \mathrm{~h} 10 \mathrm{~min}$.

FIORILLO, Celso Antonio Pacheco. Curso de direito ambiental brasileiro. 12. ed. rev., atual. eampl. São Paulo, SP: Saraiva, 2011.

LIPPMAN, Ernesto. Testamento Vital: o direito à dignidade. São Paulo: Matrix, 2013.

MARRERIRO, Cecília Lôbo. O direito à morte digna: uma análise ética e legal da ortotanásia. Curitiba: Appris, 2014.

MOLLER, Letícia Ludwing. Direito à morte com dignidade e autonomia. Curitiba: Juruá, 2012.

MORAES, Alexandre de. Direitos humanos fundamentais: teoria geral, comentário aos arts. $1^{\circ}$ a $5^{\circ}$ da Constituição da República Federativa do Brasil, doutrina e jurisprudência. 8. ed. São Paulo: Atlas, 2007.

PINHO, Rodrigo César Rebello. Teoria geral da Constituição e direitos fundamentais. 3.ed. rev. São Paulo: Saraiva, 2002.

SARLET, Ingo Wolfgang (Org.). Dimensões da dignidade: ensaio de filosofia do direito e direito constitucional. Porto Alegre, RS: Livraria do Advogado, 2005.

TAVARES, André Ramos. Curso de direito constitucional. 7. ed. São Paulo: Saraiva, 2009. 